\title{
SYNCHRONOUS AND LONGITUDINAL EFFECTS OF EMPLOYEE COMMITMENT ON INTELLECTUAL, SOCIAL AND AFFECTIVE ENGAGEMENT
}

\author{
Husam Mahmmud Jamil ABU-HAMOUR
}

\author{
Department of Business Administration, Faculty of Business, Al-Balqa Applied University, Salt, Jordan \\ E-mail:dr.husamabuhamour@bau.edu.jo
}

Received 24 March 2018; accepted 04 May 2018

\begin{abstract}
The aim of this research is to examine if there are any synchronous or longitudinal effects of employee commitment on employee engagement. The former is measured as a whole construct using affective, continuous and normative dimensions of commitment introduced by Allen and Mayer (1990), while the latter is assessed by intellectual, social and affective dimensions of employee engagement suggested by Soane et al. (2012). The rationale behind conducting this research is twofold. First, to fill the gap resulted from paucity of research conducted to examine the effects of employee commitment on employee engagement. Second, to overcome the most common limitation cited in many prior studies, namely the cross-sectional research design by performing a longitudinal research. The questionnaire used in this research is built by adopting items form prior literature. Then, it was administered over a two-time period to employees working in a large Jordanian hospitality setting located in Amman, the capital of Jordan. Two waves of data collection process have been achieved with a lag time of 12 months, that is, from August 2016 to August 2017. The number of returned questionnaires in the first measurement period is 487 (97.4\%), while the number of returned questionnaires in the second measurement period is 473 (94.6\%). The research hypotheses focus on the presence of synchronous or longitudinal effects of employee commitment, as well as intellectual, social, and affective dimensions of employee engagement. The results indicate that employee commitment significantly as well as simultaneously affects employees' intellectual engagement, while significantly and longitudinally affects their social and affective engagement. These findings contribute to the organizational behavior literature by showing that employee commitment does not only enhance employees' immediate absorption in methods that could be used to improve the work, but also it builds up strong relationships among them and with their organization's values and environment. Additionally, it boosts their emotional attachment to job tasks over time. Therefore, it is recommended that academic researchers along with practitioners should look at changes in employee attitudes that might occur in the future.
\end{abstract}

Keywords: employee commitment, intellectual engagement, social engagement, affective engagement.

JEL Classification: M12, O30.

\section{Introduction}

Employee commitment and employee engagement are examples of employee attitudinal behaviors that result in numerous positive outcomes, either for the organization or the employee himself. Apart from viewpoints that regard these attitudes as interchangeable variables, viewpoints that consider employee commitment as a component of employee engagement (Zajkowska 2012) or viewpoints that deem the latter as an ingredient of employee commitment, are adopted in this research. Moreover, in accordance with Meyer and Gagne (2008), who separately have examined these terms in order to provide new sights on the effects of employee commitment on employee engagement, the current research has been planned and carried out this research as a longitudinal one. Reviewing the literature searching for longitudinal relationships between employee commitment and employee engagement has resulted in rare findings. Therefore, conducting a research to examine longitudinal effects between these two variables will provide a good contribution to the body of organizational behavior. The majority of research covers the relationship between employee commitment and employee engagement

\footnotetext{
Copyright (c) 2018 The Authors. Published by VGTU Press.

This is an Open Access article distributed under the terms of the Creative Commons Attribution License (http://creativecommons.org/licenses/by/4.0/), which permits unrestricted use, distribution, and reproduction in any medium, provided the original author and source are credited..
} 
is a cross-sectional research. Employee engagement has been employed by researchers as independent, mediating as well as dependent variable. Singh and Karki (2015) have explored the simultaneous effect of organizational commitment and employee job engagement on organizational performance.

Albdour and Altarawneh (2014) have investigated the relationships between employee engagement and organizational commitment. Examples of studies used employee engagement as a mediating variable include Bedarkar and Pandita (2014) who have considered the mediating role of employee engagement in the relationship between drivers of employee engagement such as leadership, communication, and work-life balance and organizational performance. AlTit and Hunitie (2015) also have investigated the mediating role of employee engagement in the relationship between antecedents and consequences. In another line of research, employee engagement has been used as a dependent variable that can be predicted by numerous factors. Park et al. (2017) have studied the effect of empowering leadership on employee job engagement. Aktar and Pangil (2017) have considered the effect of human resource practices, career advancement, job security, and performance feedback on employee engagement. Balay-Odao (2017) has explored the correlation between organizational commitment and employee engagement.

Stephanie and Gustomo (2015) have analyzed the factors that affect employee engagement. Al-Tit and Hunitie (2015) have identified the impact of twelve factors on employee engagement. Deshwal (2015) has measured the influence of employee job satisfaction on his engagement. On the other hand, many studies have been conducted to review the literature of employee engagement, e.g. Carasco-Saul et al. (2015), Kavya and Padmavathy (2017) and Magem (2017). Commitment and engagement at the organization or individual levels in longitudinal studies have been found in Hakanen et al. (2008) who studied the cross-lagged relationships among job demand and resources, burnout, depression, organizational commitment and work engagement. Durksen and Klassen (2012) have asserted that both of commitment and engagement are changeable attitudes. In his Handbook of Employee Commitment, Meyer (2016) has reported the need for additional research on longitudinal effects of employee commitment on employee engagement.

\section{Literature review and hypotheses development}

\subsection{Employee engagement}

Many perspectives on employee engagement have been found in organizational behavior literature. This term has been defined as a state in which an employee is related physically, cognitively and emotionally to his job (Xanthopoulou et al. 2009). Accordingly, an engaged employee is the one who spares no effort to perform job tasks with a great concentration as an inspired individual as well as pride to work for an organization. Schaufeli et al. (2006) have regarded engagement as a positive state of mind which can be distinguished by employee's positive efforts, feelings and involvement. Khan (1990) has been the first one who defined employee engagement as a multi-dimensional construct covering three main dimensions: physical, cognitive and emotional dimensions. Bedarkar and Pandita (2014) have provided chronological definitions of employee engagement since Goffman (1961) to Cook (2012). Based on their paper, several themes of employee engagement have been derived. It has been observed that this term is equal to or at least leads to many other concepts such as employee involvement, and employee dedication of physical, cognitive and emotional competencies for the benefit of the organization, particularly during the performance of job tasks and activities, and employee citizenship behavior.

According to Ahlowalia et al. (2014), the cognitive dimension of employee engagement refers to beliefs of employees about the organization itself, its managers as well as operating conditions. The feelings of employees toward these three factors refer to the emotional dimension of employee engagement. On the other hand, the physical efforts made by employees to perform their task roles describe the physical dimension of employee engagement. Schaufeli et al. (2002) have conceptualized engagement in terms of three dimensions: vigor, dedication, and absorption. From Mackay et al's (2017) point of view, vigor means that employees make every effort to do their job tasks. Moreover, employee feelings, inspiration, pride and challenge are facets of employee dedication. The authors have added that the absorbed employee is the one who is fully concentrated in his job. Based on Khan (1990), Soane et al. (2012) have developed a scale of employee engagement covers three main dimensions: intellectual engagement, social engagement and affective engagement. They have defined intellectual engagement in terms of individuals' cognitive absorption in work and methods that can be used to enhance it. According to them, social engagement characterizes the social linkage of individuals with each other and with work environment in addition to their shared values. Finally, affective engagement, the third dimension, refers to individuals positive emotions regarding their roles.

\subsection{Employee commitment}

Commitment can be defined as a psychological state in which an employee is bonded to his organization (Allen and Mayer 1990). The authors have conceptualized commitment in terms of three dimensions: affective commitment, continuous commitment and normative commitment. Mayer and Allen (1991) have outlined commitment in 
terms of three words: desire, need and obligation. Thang and Fassin (2017) have replaced the need by the cost. The first one refers to affective commitment, while the second relates to continuous commitment, and the third describes normative commitment.

According to Cesário and Chambel (2016), an employee with a high level of affective commitment can be distinguished by his want to stay and his pride of being one of the organization members. While the main motivation of the employee in this type of commitment depends on his emotions, his motivation in continuous commitment relates to the cost experienced if he leaves the organization. Therefore, many researchers have described this type of commitment as a calculative commitment. On the other hand, the normative commitment refers to employee's moral bond that attaches him to the organization.

\subsection{Effects between employee commitment and em- ployee engagement}

It can be said that very rare research on the relationship between employee commitment and employee engagement has been conducted particularly through longitudinal designs. However, in their study on the relationship between employee engagement and organizational commitment, Albdour and Altarawneh (2014) have found a positive relationship between these two constructs. They have measured employee engagement using two dimensions: job and organizational engagement; moreover, they measured organizational commitment by utilizing three dimensions: affective, continuous and normative commitment. However, a key limitation of their study has been employing the cross-sectional design. Using a sample consisted of 105 employees from six public and private organizations, the results of Agyemang and Ofei (2013) have revealed a significant relationship between employee engagement and commitment. Also worth noting, the same limitation, the cross-sectional design of the study, has been encountered.

Saks (2006) has tested a model of antecedents and consequences of engagement, i.e. job and organization engagement indicate that there is a significant relationship between employee engagement and organizational commitment. Gathering data from employees from healthcare settings in Finland and testing the association between well-being and work commitment as well as work engagement, Kanste (2011) has detected a positive relationship between work commitment and engagement. According to Rhoades et al. (2001), affective commitment is one of employee engagement antecedents. According to Crawford et al. (2010) and A. Khalid and S. Khalid (2015), employee engagement is positively related to employee commitment. Gupta (2017) has indicated that corporate social responsibility is positively associated with organizational commitment in the presence of employee engagement. Using a sample of employees in a large mining organization in Australia, Albrecht (2012) has tested a model consists of six variables: job, team and organizational resources, employee well-being, employee engagement, employee commitment and extra-role performance. Out of the results, engagement was positively related to commitment. Nonetheless, a key limitation cited in the above-mentioned studies has been utilizing the cross-sectional design in those studies (Cesário and Chambel 2016, Geldenhuys et al. 2014). In contrast, the current research sought to investigate if there are any longitudinal effects of employee commitment and employee engagement as measured by intellectual, social and affective engagement, by suggesting three hypotheses:

$\mathrm{H}_{1 \mathrm{a}}$ : Employee commitment has a significant synchronous effect on employee intellectual engagement

$\mathrm{H}_{1 \mathrm{~b}}$ : Employee commitment has a significant longitudinal effect on employee intellectual engagement

$\mathrm{H}_{2 \mathrm{a}}$ : Employee commitment has a significant synchronous effect on employee social engagement

$\mathrm{H}_{2 \mathrm{~b}}$ : Employee commitment has a significant longitudinal effect on employee social engagement

$\mathrm{H}_{3 \mathrm{a}}$ : Employee commitment has a significant synchronous effect on employee affective engagement

$\mathrm{H}_{3 \mathrm{~b}}$ : Employee commitment has a significant longitudinal effect on employee affective engagement

\section{Research methodology}

\subsection{Research design}

This research was designed as a longitudinal research. One of the most important features of this design is the possibility of collecting data over time from the same individuals or organizations (Ployhart and Vandenberg 2010). For the current research, data were recollected from the same organizations. The first wave of data was collected in August 2016 while the second wave was collected at the end of August 2017, with a time lag of 12 months. Data were analyzed by following longitudinal studies such as Xanthopoulou et al. (2009), De Lange et al. (2008) and Brouwers and Tomic (2000).

\subsection{Research sample and data collection}

The sample of this research consisted of employees who are working in a large hospitality setting in Jordan. A total of 500 employees were selected as a representative sample of the research population. All members of the sample were administered 500 questionnaires to collect data. The researcher seeks to achieve a high response rate, therefore decided to distribute questionnaires to respondents by hand. The number of returned questionnaires in the first measurement period was 487 (97.4\%), while the number of returned questionnaires in the second measurement period was 473 (94.6\%). 


\subsection{Research model and analysis procedures}

Figure 1 displays the initial research model that has been proposed to examine the mutual effects between employee commitment (EC) and employee engagement (EE).

Figure 2 exhibits the mutual effects of EC and three dimensions of EE: intellectual engagement (IE), social engagement (SE) and affective engagement (AE).

On the basis of the detailed research model in Figure 2, three main models were extracted to test presumed effects among research variables. As can be recognized from the figure, model 1 represents the effects between EC and IE, model 2 illustrates the effects between EC and SE, and model 3 characterizes the effects between EC and AE. Precisely, each model in Figure 2 enfolds five models: null model,

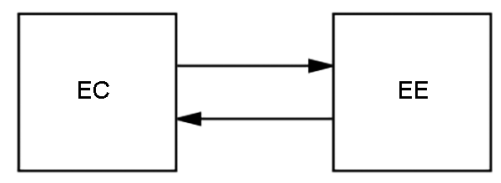

Figure 1. Initial research model

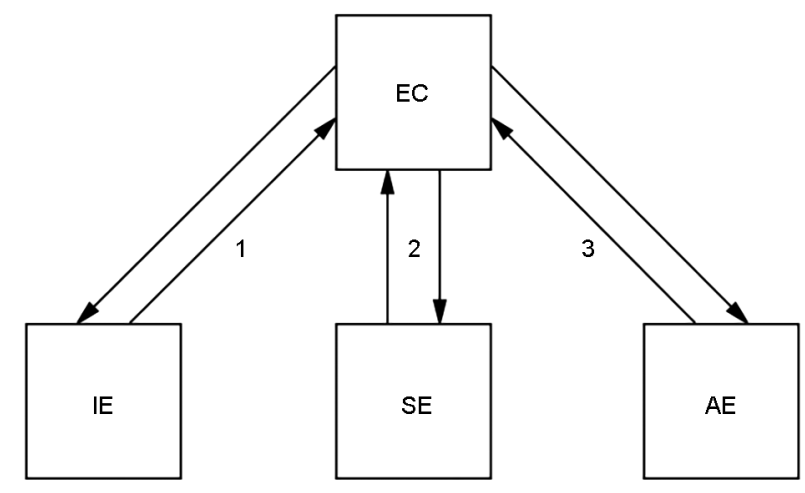

Figure 2. Detailed research model

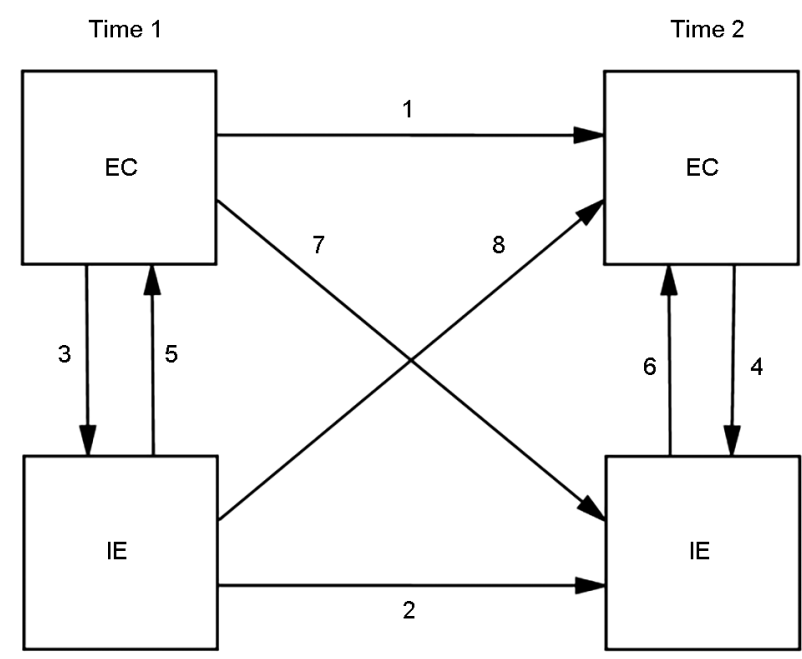

Figure 3. Stability, synchronous and longitudinal paths of the effects among EC and IE stability model, two synchronous models of type 1 and 2 and two longitudinal models. Figures 3, 4 and 5 show stability, synchronous and longitudinal models enveloped in the three main models in Figure 2.

Examination of the effects in models unfolded in Figures 3, 4 and 5 was found in the strength of the steps advance by Brouwers and Tomic (2000). The authors have promoted four steps to compare models and to test the direction of relationships among research variables over time. For the current research, the same steps were adopted in order to investigate the effects between EC and three dimensions of EE: IE, SE and AE. The aim of step 1 was to identify the significance of the stability model by comparing it to the null model. In other words, this step explores changes happened to the same variables over time, i.e. from time 1 to time 2. Coefficients of regression for all paths except for paths 1 and 2 were fixed at zero. For Brouwers and Tomic

Time 1

Time 2

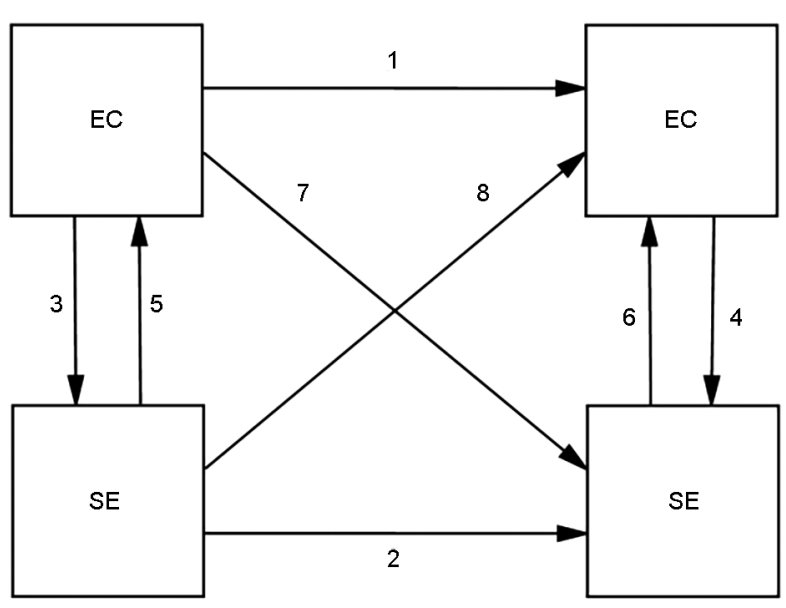

Figure 4. Stability, synchronous and longitudinal paths of the effects among EC and SE

Time 1

Time 2

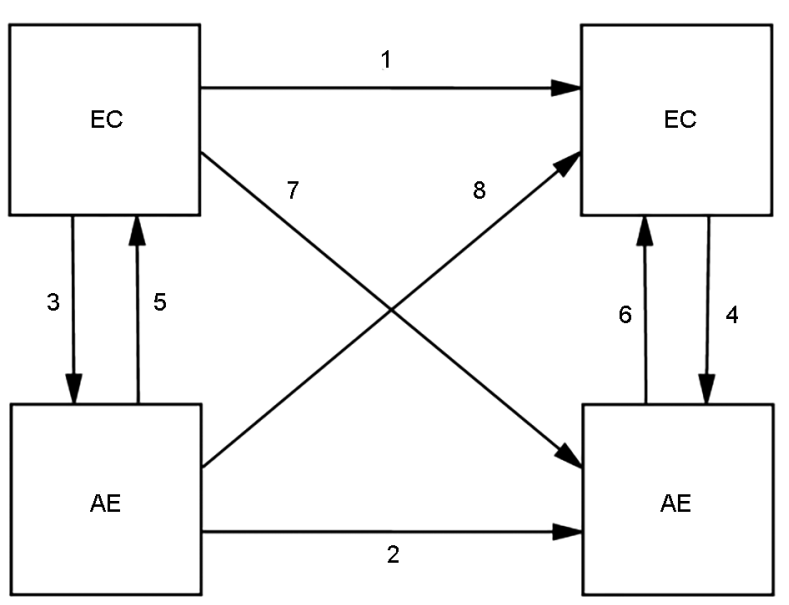

Figure 5. Stability, synchronous and longitudinal paths of the effects between EC and AE 
(2000), the null model was used as a baseline model in the first step only. Then in the analysis, it was replaced by the stability model in steps 2 to 4 .

The purpose of step 2 is to explore the significance of synchronous paths by comparing two synchronous type 1 models with the stability model. That is, comparing stability paths 1 and 2 with synchronous paths 3 and 4 . In this step, coefficients of regression for all paths except paths 1, 2, 3 and 4 were fixed at zero. In their study on the relationships between job resources and work engagement, the first or baseline model used by De Lange et al. (2008) has been the stability model which includes effects between stability and synchronous paths. In their longitudinal study on job resources and work engagement, Xanthopoulou et al. (2009) have used four models, the first one has been the stability model in which stability and synchronous paths are included, while lagged paths were excluded. Pursuing Brouwers and Tomic (2000), synchronous models used in step 2 in this research are called type 1 synchronous models, while those used in the next step are called type 2 synchronous models. The difference between synchronous type 1 and type 2 models is that the latter is subject to equality assumption. The aim of step 3 was to compare the best-fitted type 1 synchronous model, as was revealed in step 2 , with two new type 2 synchronous models, i.e. synchronous paths of time 1 and time 2 that go in the same direction, which are paths 3 and 4 . Explicitly, stability paths 1 and 2 were set free while synchronous type 2 paths were derived to be equivalent. All other paths, i.e. 5, 6, 7 and 8 were fixed at zero. Step four was formulated to analyze the significance of lagged paths by comparing the longitudinal paths with the synchronous type 2 paths. In this step, the stability paths 1 and 2 in addition to one of the longitudinal paths, specifically lagged path 7, were released. Concurrently, the synchronous paths (paths 3 and 4) which administered in the same direction similar to the direction of the lagged path (path 7), were assumed to be equal. Other paths (synchronous paths 5, 6 and lagged path 8 ) were fixed at zero.

\subsection{Questionnaire development}

Employee engagement was assessed using the ISA engagement scale that has been developed by Soane et al. (2012) The scale consisted of three main dimensions: intellectual engagement, social engagement, and affective engagement. Each of the dimensions was measured using three items. According to the researchers, ISA scale relies on the basis of alpha value that reached 0.88 . For dimensions of the ISA scale, alpha values were 0.88 for intellectual engagement, 0.95 for social engagement and 0.95 for affective engagement. Examples of items used to measure employee engagement include "I am fully concentrated when doing my work", "I share common organizational values with my co-workers" and "I am enthusiastic to perform my job". ISA engagement scale was adopted by other studies such as Sharma (2016) who has used the scale to measure the degree of employee engagement and to identify the effect of some personal characteristics on ISA engagement. Employee commitment was measured using the three dimensions that have been suggested by Allen and Mayer (1990), which are: affective commitment, continuous commitment and normative commitment. The scale was anchored using fivepoint Likert scale ranging from 1 (strongly disagree) to 5 (strongly agree). The value of Cronbach's alpha of the scale was 0.756 . The same scale was used by numerous studies like Singh and Karki's (2015) study that has been carried out to explore the influence of employee engagement and commitment on organizational performance.

\section{Hypotheses testing}

\subsection{Employee commitment and intellectual engagement}

In the first step of the analysis, path 1 and path 2 were released while the other paths, namely 3, 4, 5, 6, 7 and 8 were set to zero. As stated earlier, the aim of this step was to explore the significance of the stability model by comparing it with the null model. Figure 6 shows that only two paths, namely path 1 and 2 were released and other paths were fixed at zero.

As shown in Table 1, the stability model was found to be significantly distinguished based on chi-square difference and goodness of fit indices ( $\Delta \chi^{2}$ stab. $=406.5, \mathrm{P}=0.000$, AGFI stab. $=0.903$, AGFI null $=0.385$, CFI stab. $=0.923$ ). Therefore, both of employee commitment in time 1 (EC1) and intellectual engagement in time 1 (IE1) were allowed to be regressed on employee commitment in time 2 (EC2) and intellectual engagement in time 2 (IE2).

In the second step, three models were compared: the stability model and the two synchronous type 1 models. That is, four paths of those depicted in Figure 3 were released: 1,2,3 and 4. The other paths, i.e. 5, 6, 7 and 8 were fixed at zero as shown in Figure 7. The results in Table 1 indicated that the synchronous type 1 models were significantly more preferable than the stability model. Moreover, the synchronous type 1 path (EC1 $\rightarrow$ IE1) was significantly more preferable than the other synchronous path $\left(\Delta \chi^{2}: \mathrm{EC} 1\right.$

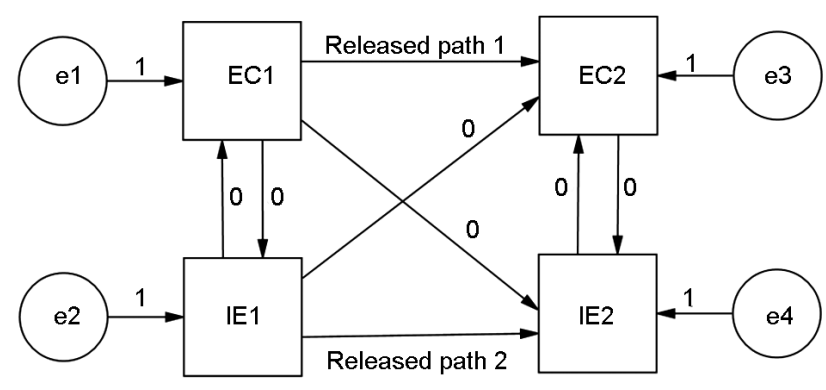

Figure 6. Exploring the significance of the stability model 


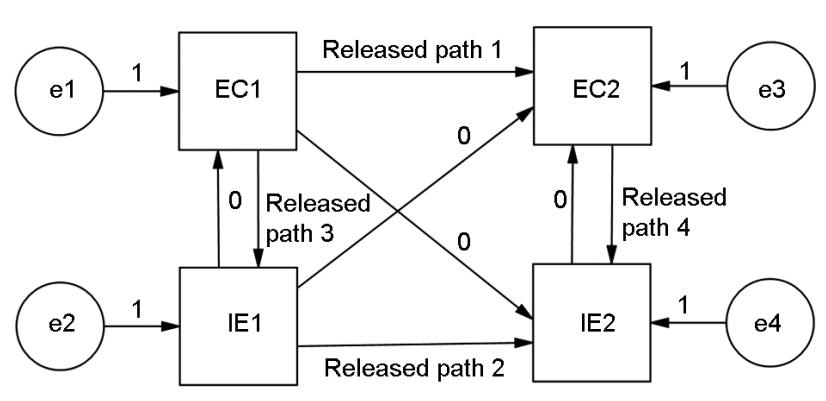

Figure 7. Exploring the significance of synchronous type 1 models

Table 1. Results of the effect of employee commitment on intellectual engagement

\begin{tabular}{|l|l|c|c|c|c|}
\hline EC $\rightarrow$ IE & Model & $\Delta \chi^{2}$ & $P$ & AGFI & CFI \\
\hline \multirow{4}{*}{ Step 1 } & Null & - & - & 0.385 & 0.558 \\
\cline { 2 - 6 } & Stability & 406.5 & 0.000 & 0.703 & 0.723 \\
\hline \multirow{4}{*}{ Step 2 } & Synch. 1 & & & & \\
\cline { 2 - 6 } & EC $\rightarrow$ IE & 71.10 & 0.000 & 0.985 & 1.000 \\
\cline { 2 - 6 } & IE $\rightarrow$ EC & 69.30 & 0.000 & 0.884 & 0.832 \\
\hline \multirow{4}{*}{ Step 4 } & Synch. 2 & & & & \\
\cline { 2 - 6 } & EC $\rightarrow$ IE & 63.01 & 0.000 & 0.912 & 0.863 \\
\cline { 2 - 6 } & IE $\rightarrow$ EC & 47.13 & 0.000 & 0.770 & 0.548 \\
\hline & Long. & & & & \\
\cline { 2 - 6 } & EC $\rightarrow$ IE & 66.12 & 0.000 & 0.943 & 0.940 \\
\cline { 2 - 6 } & IE $\rightarrow$ EC & 53.40 & 0.000 & 0.751 & 0.773 \\
\hline
\end{tabular}

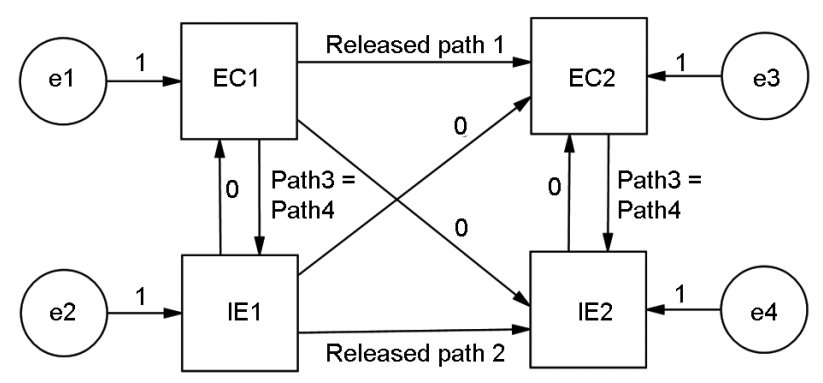

Figure 8. Exploring the significance of synchronous type 2 models

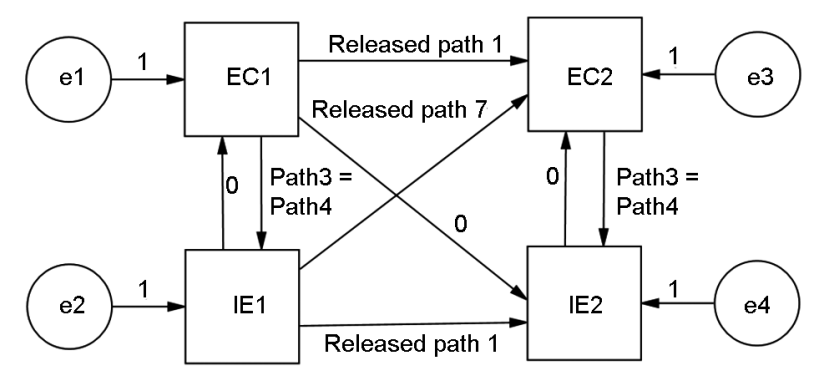

Figure 9. Exploring the significance of the longitudinal models $\rightarrow$ IE $1=71.10,\left(\Delta \chi^{2}: \mathrm{EC} 2 \rightarrow \mathrm{IE} 2=69.30, \mathrm{P}=0.000, \mathrm{AGFI}:\right.$ $\mathrm{EC} 1 \rightarrow \mathrm{IE} 1=0.985, \mathrm{AGFI}: \mathrm{EC} 2 \rightarrow \mathrm{IE} 2=0.884, \mathrm{CFI}: \mathrm{EC} 1$ $\rightarrow$ IE1 $=1.000, \mathrm{CFI}: \mathrm{EC} 2 \rightarrow \mathrm{IE} 2=0.832$ ). Consequently, the best fitting model was accepted to be compared with the synchronous type 2 models.

In the third step, two synchronous models of type 2 were compared to the best fitting synchronous type 1 model explored in step 2. As can be seen in Figure 7, stability paths 1 and 2 were released; synchronous paths 3 and 4 were constrained to be equal, while the other paths, 5, 6, 7 and 8 were fixed at zero.

Paths 3 and 4 that go in the same direction were released in step 2 . The same paths were subject to equality assumption in step three. The results of step 3 depicted in Table 2 indicated that both synchronous type 2 models were not significantly superior to the synchronous type 1 model that detected in step 2 as the best fitting model $\left(\Delta \chi^{2}:\right.$ the best-fitting synch. $1 \mathrm{EC} \rightarrow \mathrm{IE}=71.10,\left(\Delta \chi^{2}\right.$ : synch. $2 \mathrm{EC}$ $\rightarrow \mathrm{IE}=63.01, \Delta \chi^{2}$ : synch. $2 \mathrm{IE} \rightarrow \mathrm{EC}=47.13$, AGFI: the best-fitting synch. $1 \mathrm{EC} \rightarrow \mathrm{IE}=0.985$, AGFI: synch. 2 EC $\rightarrow \mathrm{IE}=0.912$, AGFI: synch. $2 \mathrm{IE} \rightarrow \mathrm{EC}=0.770, \mathrm{CFI}:$ the best-fitting synch. $1 \mathrm{EC} \rightarrow \mathrm{IE}=1.000, \mathrm{CFI}$ : synch. $2 \mathrm{EC} \rightarrow$ $\mathrm{IE}=0.863$, CFI: synch. $2 \mathrm{IE} \rightarrow \mathrm{EC}=0.548$ ). In a word, the results illustrated that one of the two synchronous type 2 models (EC $\rightarrow$ IE) was superior to the other (IE $\rightarrow$ EC), as shown in Figure 8. However, the best-fitting synchronous type 1 model was significantly superior to the best one of the two synchronous type 2 models.

In the final step, the stability paths $1(\mathrm{EC} 1 \rightarrow \mathrm{EC} 2)$ and 2 (IE1 $\rightarrow$ IE2) in addition to the lagged path 7 (EC1 $\rightarrow$ IE2) were released while the paths 3 (EC1 $\rightarrow$ IE1) and 4 (EC2 $\rightarrow$ IE2) were constrained to be equal. The other paths in the model, 5 (IE1 $\rightarrow$ EC1), 6 (IE2 $\rightarrow$ EC2) and 8 (IE1 $\rightarrow$ EC2) were fixed at zero, as shown in Figure 9.

It was revealed that the released lagged path of the longitudinal model was significantly exceeded the best fitting model of the two synchronous type 2 models $\left(\Delta \chi^{2}\right.$ : long. $\mathrm{EC} \rightarrow \mathrm{IE}=66.12 \mathrm{P}=0.000, \mathrm{AGFI}$ : long. $\mathrm{EC} \rightarrow \mathrm{IE}=0.943$, AGFI: synch. $2 \mathrm{EC} \rightarrow \mathrm{IE}=0.912$, CFI: long. $\mathrm{EC} \rightarrow \mathrm{IE}=$ 0.940, CFI: synch. $2 \mathrm{EC} \rightarrow \mathrm{IE}=0.863)$. The final comparison should be between the best fitting model clarified in step 4 (the longitudinal model EC $\rightarrow$ IE) and with the best fitting one brought to light in step 2 (the synchronous type 1 model EC $\rightarrow$ IE). The results in Table 1 confirmed that the synchronous type 1 model (EC $\rightarrow$ IE) fitted the data better than the longitudinal model $(\mathrm{EC} \rightarrow \mathrm{IE})$. Therefore, it was concluded that there is a significant synchronous effect of employee commitment on employee intellectual engagement.

\subsection{Employee commitment and social engagement}

The same four steps carried out in the previous section were repeated in order to examine the effect of employee 
commitment on employee social engagement. The results of these steps are shown in Table 2. It was found that the stability model was significantly preferred in comparison with the null model $\left(\Delta \chi^{2}\right.$ stab. $=377.30, \mathrm{P}=0.000$, AGFI stab. $=0.711$, AGFI null $=0.114)$. Consequently, SE at time 1 was accepted to be regressed on itself in Time 2. The results also showed that both synchronous type 1 models were significantly superior to the stability model $\left(\Delta \chi^{2}\right.$ : synch. $1 \mathrm{EC} \rightarrow \mathrm{SE}=67.03, \mathrm{P}=0.000, \Delta \chi^{2}$ : synch. $1 \mathrm{SE} \rightarrow$ $\mathrm{EC}=65.50, \mathrm{P}=0.000, \mathrm{AGFI}$ : stab. $=0.711, \mathrm{AGFI}$ : synch. 1 $\mathrm{EC} \rightarrow \mathrm{SE}=0.918$, AGFI: synch. $1 \mathrm{SE} \rightarrow \mathrm{EC}=0.887, \mathrm{CFI}:$ stab. $=0.793$, CFI: synch. $1 \mathrm{EC} \rightarrow \mathrm{SE}=0.921, \mathrm{CFI}$ : synch. $1 \mathrm{SE} \rightarrow \mathrm{EC}=0.900)$. In relation to the significant path of the two synchronous type 1 models, the results determined that the synchronous type 1 model (EC $\rightarrow \mathrm{SE}$ ) fitted the data better than the synchronous type 1 model ( $\mathrm{SE} \rightarrow \mathrm{EC}$ ).

Moreover, the results disclosed that the synchronous type 2 models were not significantly superior to the best fitting synchronous type 1 model $\left(\Delta \chi^{2}\right.$ : synch. $1 \mathrm{EC} \rightarrow \mathrm{SE}$ $=67.03, \mathrm{P}=0.000,\left(\Delta \chi^{2}:\right.$ synch. $2 \mathrm{SE} \rightarrow \mathrm{EC}=62.90, \mathrm{P}=$ 0.000 , AGFI: synch. $1 \mathrm{EC} \rightarrow \mathrm{SE}=0.918$, CFI: synch. 1 $\mathrm{EC} \rightarrow \mathrm{SE}=0.921$, AGFI: synch. $2 \mathrm{SE} \rightarrow \mathrm{EC}=0.842$, CFI: synch. $2 \mathrm{SE} \rightarrow \mathrm{EC}=0.911)$. The results in Table 2 revealed that the longitudinal model (EC $\rightarrow \mathrm{SE}$ ) was significantly superior to the best fitting model of the two synchronous type 2 models $\left(\Delta \chi^{2}\right.$ : long. $\mathrm{EC} \rightarrow \mathrm{SE}=72.11, \mathrm{P}=0.000, \Delta \chi^{2}$ : synch. $2 \mathrm{EC} \rightarrow \mathrm{SE}=62.90, \mathrm{P}=0.000$, AGFI: long. $\mathrm{EC} \rightarrow$ $\mathrm{SE}=0.964$, AGFI: synch. $2 \mathrm{SE} \rightarrow \mathrm{EC}=0.842$, CFI: long. $\mathrm{EC} \rightarrow \mathrm{SE}=0.958$, CFI: synch. $2 \mathrm{SE} \rightarrow \mathrm{EC}=0.917$ ). Finally, the results ascertained that the longitudinal model with the released lagged path (EC $\rightarrow \mathrm{SE}$ ) fitted the data better than the best fitting synchronous type 1 model $(\mathrm{EC} \rightarrow \mathrm{SE})\left(\Delta \chi^{2}\right.$ : long. $\mathrm{EC} \rightarrow \mathrm{SE}=72.11, \mathrm{P}=0.000, \Delta \chi^{2}$ : synch. $1 \mathrm{EC} \rightarrow \mathrm{SE}$ $=67.03, \mathrm{P}=0.000$, AGFI: long. $\mathrm{EC} \rightarrow \mathrm{SE}=0.964$, AGFI: long. $\mathrm{SE} \rightarrow \mathrm{EC}=0.947$, AGFI: synch. $1 \mathrm{EC} \rightarrow \mathrm{SE}=0.918$, $\mathrm{CFI}$ : long. $\mathrm{EC} \rightarrow \mathrm{SE}=0.958, \mathrm{CFI}:$ long. $\mathrm{SE} \rightarrow \mathrm{EC}=0.958$, $\mathrm{CFI}$ : synch. $1 \mathrm{EC} \rightarrow \mathrm{SE}=0.921)$. Hence, it was revealed that the longitudinal model with the released path $(\mathrm{EC} \rightarrow$ SE) best fitted the data. Based on these results, there was a significant longitudinal effect of employee commitment on employee social engagement.

\subsection{Employee commitment and affective engagement}

Table 3 exhibits the results of the four steps run to peruse the effects between employee commitment and affective engagement. The table highlights that the stability model was significantly superior to the null model $\left(\Delta \chi^{2}\right.$ stab. $=$ 389.12, $\mathrm{P}=0.000$, AGFI stab. $=0.701$, AGFI null $=0.200$ ). Therefore, $\mathrm{AE}$ at time 1 was accepted to be regressed on itself in Time 2.

The results also showed that both of the synchronous type 1 models were significantly superior to the stability model $(\Delta \chi 2$ : synch. $1 \mathrm{EC} \rightarrow \mathrm{AE}=70.01, \mathrm{P}=0.000, \Delta \chi 2$ :
Table 2. Results of the effect of employee commitment on social engagement

\begin{tabular}{|l|l|c|c|c|c|}
\hline EC $\rightarrow$ SE & Model & $\Delta \chi^{2}$ & $P$ & AGFI & CFI \\
\hline \multirow{4}{*}{ Step 1 } & Null & - & - & 0.114 & - \\
\cline { 2 - 6 } & Stability & 377.30 & 0.000 & 0.711 & 0.793 \\
\hline \multirow{4}{*}{ Step 2 } & Synch. 1 & & & & \\
\cline { 2 - 6 } & EC $\rightarrow$ SE & 67.03 & 0.000 & 0.918 & 0.921 \\
\cline { 2 - 6 } & SE $\rightarrow$ EC & 65.50 & 0.000 & 0.887 & 0.900 \\
\hline \multirow{4}{*}{ Step 3 } & Synch. 2 & & & & \\
\cline { 2 - 6 } & EC $\rightarrow$ SE & 61.13 & 0.000 & 0.801 & 0.841 \\
\cline { 2 - 6 } & SE $\rightarrow$ EC & 62.90 & 0.000 & 0.842 & 0.911 \\
\hline \multirow{3}{*}{ Step 4 } & Long. & & & & \\
\cline { 2 - 6 } & EC $\rightarrow$ SE & 72.11 & 0.000 & 0.964 & 0.958 \\
\cline { 2 - 6 } & SE $\rightarrow$ EC & 69.78 & 0.000 & 0.947 & 0.917 \\
\hline
\end{tabular}

Table 3. Results of the effect of employee commitment on affective engagement

\begin{tabular}{|l|l|c|c|c|c|}
\hline $\mathrm{EC} \rightarrow \mathrm{AE}$ & Model & $\Delta \chi^{2}$ & $\mathrm{P}$ & AGFI & CFI \\
\hline \multirow{3}{*}{ Step 1 } & Null & - & - & 0.200 & - \\
\cline { 2 - 6 } & Stability & 389.12 & 0.000 & 0.701 & 0.791 \\
\hline \multirow{4}{*}{ Step 2 } & Synch. 1 & & & & \\
\cline { 2 - 6 } & EC $\rightarrow$ AE & 71.01 & 0.000 & 0.927 & 0.914 \\
\cline { 2 - 6 } & AE $\rightarrow$ EC & 70.48 & 0.000 & 0.920 & 0.879 \\
\hline \multirow{4}{*}{ Step 3 } & Synch. 2 & & & & \\
\cline { 2 - 6 } & EC $\rightarrow$ AE & 58.14 & 0.000 & 0.921 & 0.900 \\
\cline { 2 - 6 } & AE $\rightarrow$ EC & 60.22 & 0.000 & 0.922 & 0.900 \\
\hline \multirow{4}{*}{ Step 4 } & Long. & & & & \\
\cline { 2 - 6 } & EC $\rightarrow$ AE & 74.44 & 0.000 & 0.967 & 1.000 \\
\cline { 2 - 6 } & AE $\rightarrow$ EC & 73.00 & 0.000 & 0.951 & 0.988 \\
\hline
\end{tabular}

synch. $1 \mathrm{AE} \rightarrow \mathrm{EC}=70.48, \mathrm{P}=0.000$, AGFI: stab. $=0.711$, AGFI: synch. $1 \mathrm{EC} \rightarrow \mathrm{AE}=0.927$, AGFI: synch. $1 \mathrm{AE} \rightarrow$ $\mathrm{EC}=0.924$, CFI: stab. $=0.791, \mathrm{CFI}$ : synch. $1 \mathrm{EC} \rightarrow \mathrm{AE}$ $=0.886$, CFI: synch. $1 \mathrm{AE} \rightarrow \mathrm{EC}=0.879)$. On the other hand, the results confirmed that both of the synchronous type 2 models were significantly lesser in comparison with the best fitting synchronous type 1 model $(\mathrm{EC} \rightarrow \mathrm{AE})\left(\Delta \chi^{2}\right.$ : synch. $1 \mathrm{EC} \rightarrow \mathrm{AE}=71.01, \mathrm{P}=0.000, \Delta \chi^{2}:$ synch. $2 \mathrm{EC} \rightarrow$ $\mathrm{AE}=58.14, \mathrm{P}=0.000, \Delta \chi^{2}:$ synch. $2 \mathrm{AE} \rightarrow \mathrm{EC}=60.22, \mathrm{P}$ $=0.000$, AGFI: synch. $1 \mathrm{EC} \rightarrow \mathrm{AE}=0.927$, AGFI: synch. $2 \mathrm{EC} \rightarrow \mathrm{AE}=0.921$, AGFI: synch. $2 \mathrm{AE} \rightarrow \mathrm{EC}=0.922)$.

Moreover, longitudinal models were found to be significantly superior to the best fitting model of the synchronous type 2 models $\left(\Delta \chi^{2}\right.$ : long. $\mathrm{EC} \rightarrow \mathrm{AE}=74.44, \Delta \chi^{2}$ : synch. $2 \mathrm{AE} \rightarrow \mathrm{EC}=60.22$, AGFI: long. $\mathrm{EC} \rightarrow \mathrm{AE}=0.967, \mathrm{CFI}:$ long. $\mathrm{EC} \rightarrow \mathrm{AE}=1.000$, $\mathrm{AGFI}:$ synch. $2 \mathrm{AE} \rightarrow \mathrm{EC}=0.900$, CFI: synch. $2 \mathrm{AE} \rightarrow \mathrm{EC}=0.900$ ). Particularly, the results demonstrated that the best fitting longitudinal model (EC $\rightarrow$ $\mathrm{AE}$ ) fitted the data better than the best fitting synchronous 
type 1 model. Consequently, there was a significant longitudinal effect of employee commitment on employee affective engagement.

\section{Discussion and conclusion}

Though employee commitment and employee engagement were used interchangeably in literature and practice, Kanste (2011) has found that these terms can be treated differently. Both of them have been regarded as critical success factors for organizations (Cesário and Chambel 2016). Hence, they are on managers' agenda nowadays (Huang et al. 2017). Many perceptions on employee engagement have been derived from the literature. According to Bedarkar and Pandita (2014), engaged employees are crucial assets that can be utilized to increase the organization strategic competency. The results of Al-Tit and Hunitie (2015) highlighted the importance of employee engagement in which this variable has been found to play a significant role as a mediator in the relationship between numerous factors, e.g. organizational justice, culture and support, and job satisfaction. The significance of employee commitment has also been underlined in many studies to have different implications such as organizational effectiveness (Oluwalope and Sunday 2017). Despite the little studies carried out on the relationship between employee commitment and employee engagement, it has been observed that the majority of the available studies are cross-sectional studies from which only synchronous effects can be drawn.

This research aimed at examining the presence of effects, be it synchronous or longitudinal, among employee commitment and three dimensions of employee engagement: intellectual, social and affective engagement through testing six hypotheses; three of which are related to synchronous effects of employee commitment on dimensions of employee engagement; three are concerned on longitudinal effects of employee commitment on dimensions of employee engagement. The research comprised three inclusive models. Each of them encompassed one null model, one stability model, two synchronous models of type 1, two synchronous models of type 2 and two longitudinal models. Model number 1 illustrated in Figure 3 was used to test the effects between employee commitment and intellectual engagement over time. On the other hand, model number 2 depicted in Figure 4 was applied to investigate the effects between employee commitment and social engagement over time. Finally, model number 3 was utilized in order to probe the effects between employee commitment and affective engagement.

In terms of the effects of employee commitment on employee intellectual engagement, the results indicated that employee commitment had a significant synchronous effect on employee intellectual engagement. In fact, this result was built on the finding of the final step of testing the effects of employee commitment on employee engagement in which the synchronous model (EC $\rightarrow$ IE) was found to be the best model fitted the data. In other words, hypothesis $1 \mathrm{a}$ was accepted and hypothesis $1 \mathrm{~b}$ was rejected. According to Sharma (2016), intellectual engagement refers to employee's cognitive absorption in his job related tasks. The synchronous effect of employee commitment on employee intellectual engagement can be explained by assuming that employee cognitive concentration focuses on his daily tasks which lead to the their overall performance on job in the present period of time. This synchronous effect might also be understood in favor of employee engagement development. Khalid et al. (2015) have defined employee intellectual engagement in terms of his effort to better perform job tasks. That is, the employee is still in the first phase of engagement, which will extend in future into other types of engagement such as affective or social engagement. Relative to the effects of employee commitment on employee social engagement, the results of the analysis pointed out that the longitudinal model $(\mathrm{EC} \rightarrow \mathrm{SE}$ ) was the model that best fitted the data. Therefore, employee commitment had a significant longitudinal effect on employee social engagement. Based on this result, hypothesis $2 \mathrm{a}$ was rejected and hypothesis $2 \mathrm{~b}$ was supported. According to Khalid et al. (2015), social engagement refers to employee's talking with social groups about work experiences and efforts exerted to improve ways of performing job tasks. In line with employee engagement development explanation, an employee talks with colleagues about a job after he experienced that job not during the performance of the job. In one word, one can conclude that employee social engagement is a consequence stage of intellectual engagement. Therefore, the nature of effect of commitment on social engagement was longitudinal.

Finally, the results underlined that the longitudinal model (EC $\rightarrow \mathrm{AE}$ ) was the best model fitted the data, which means that employee commitment had a significant longitudinal effect on employee affective engagement. On the basis of this result, hypothesis $3 \mathrm{a}$ was rejected and hypothesis $3 \mathrm{~b}$ was accepted. Trofimov et al. (2017) have defined employee affective engagement in relation to his positive feelings about doing job tasks. The researcher thinks of affective engagement as a succeeding stage after intellectual engagement. That is why employee commitment had a longitudinal effect on employee affective engagement. The results confirmed by this research are summarized in Table 4. In accordance with these results, it was concluded that the design of research plays an important role in examining different effects among variables over time. The current research was designed to be longitudinal in order to achieve two purposes which are the direction of the relationships between variables and the time frame in which these relationships has been built. A key conclusion of this research is 
that the psychological bond between the employee and the organization represented by his desire to stay working at the organization, his need to avoid or incurred any leave-caused costs as well as his moral obligation toward the organization, will result over time in an engaged employee linked socially to his co-workers, work environment and organization's value, who is attached emotionally to his job tasks.

In this research, new insights on the association between employee commitment and employee engagement have been provided. The main conclusion of this research is that the effect of employee commitment does not only enhance employee intellectual engagement at the present time, but also it improves his social and affective engagement in the future.

\section{Recommendations and future research}

Based on the result that employee commitment has significant synchronous and longitudinal effects on employee engagement, organizations and academic researchers should carry on employee commitment as a two wave variable that can elevate employee behavioral attitudes such as engagement. Enhancing employee commitment will improve employee engagement now and tomorrow. Therefore, commitment oriented strategies should be formulated and executed in order to increase employee commitment. Despite this contribution, this research is still limited since there are no empirical studies can be used as a reference to compare results. On the other hand, the data collected for the purpose of this research were from the same organization but not from the same participants since it was impossible to recollect data from the same employees, particularly in the second wave of data collection which was conducted after 12 months of the first wave. A key limitation of this research emerged during the discussion of the results was the measurement of employee commitment as a whole construct. It was revealed that employee commitment should be studied in terms of its separated dimensions, i.e. affective, normative and continuous commitment in order to gain more understanding on the relationships between these dimensions and employee engagement dimensions. In relation to future research, limitations experienced in this research should be tackled in future studies. A reverse influence of employee engagement on employee commitment was found by A. Khalid and S. Khalid (2015). Therefore, further studies are required to examine the presence of any reciprocal relationship among employee commitment and employee engagement. In accordance with Sharma (2016), a future research also should consider employee type and other related characteristics when studying work-related attitudes like employee engagement. That is, a new study is needed to explore if there is any difference in longitudinal effects of employee commitment on employee engagement
Table 4. Summary of hypotheses testing

\begin{tabular}{|c|c|l|c|}
\hline Hypothesis & Path & Time Frame & Result \\
\hline $\mathrm{H}_{1 \mathrm{a}}$ & EC $\rightarrow$ IE & Synchronous & $\checkmark$ \\
\hline $\mathrm{H}_{1 \mathrm{~b}}$ & $\mathrm{EC} \rightarrow$ IE & Longitudinal & $\times$ \\
\hline $\mathrm{H}_{2 \mathrm{a}}$ & EC $\rightarrow$ IE & Synchronous & $\times$ \\
\hline $\mathrm{H}_{2 \mathrm{~b}}$ & EC $\rightarrow$ IE & Longitudinal & $\checkmark$ \\
\hline $\mathrm{H}_{3 \mathrm{a}}$ & $\mathrm{EC} \rightarrow$ IE & Synchronous & $\times$ \\
\hline $\mathrm{H}_{3 \mathrm{~b}}$ & $\mathrm{EC} \rightarrow$ IE & Longitudinal & $\checkmark$ \\
\hline
\end{tabular}

in favor of employee work type, be it contractual or permanent employee, administrative or non-administrative (Khalid et al. 2015). A future research also should be consider the possibility of generalizing results for other industries, other cultures and countries.

\section{References}

Agyemang C, Ofei S (2013) Employee work engagement and organizational commitment: a comparative study of private and public sector organizations in Ghana. European Journal of Business and Innovation Research 1 (4): 20-33.

Ahlowalia S, Tiwary D, Jha A (2014) Employee engagement: a structured theoretical review. The International Journal of Business \& Management 2 (6): 309-317.

Aktar A, Pangil F (2017) The relationship between employee engagement, HRM practices and perceived organizational support: evidence from banking employees. International Journal of Human Resource Studies 7 (3): 1-22. https://doi. org/10.5296/ijhrs.v7i3.11353

Albdour A, Altarawneh I (2014) Employee engagement and organizational commitment: evidence from Jordan. International Journal of Business 19 (2): 192-212.

Albrecht S (2012) The influence of job, team and organizational level resources on employee well-being, engagement, commitment and extra-role performance. International Journal of Manpower 33 (7): 840-853. https://doi. org/10.1108/01437721211268357

Allen N, Meyer J (1990) The measurement and antecedents of organizational commitment: re-examination of the affective and continuance commitment scales. Journal of Applied Psychology 72: 638-642.

Al-Tit A, Hunitie M (2015) The mediating effect of employee engagement between its antecedents and consequences. Journal of Management Research 7 (5): 47-62. https://doi. org/10.5296/jmr.v7i5.8048

Balay-Odao E (2017) Work practice environment, organizational commitment and work engagement of emergency department nurses: a correlation study. Journal of Nursing and Care 6 (1): 1-9. https://doi.org/10.4172/2167-1168.1000380

Bedarkar M, Pandita D (2014) A study on the drivers of employee engagement impacting employee performance. Procedia Social and Behavioral Sciences 133: 106-115. https://doi. org/10.1016/j.sbspro.2014.04.174

Brouwers A, Tomic W (2000) A longitudinal study of teacher burnout and perceived self-efficacy in classroom management. 
Teaching and Teacher Education 16: 239-253. https://doi. org/10.1016/S0742-051X(99)00057-8

Carasco-Saul M, Kim W, Kim T (2015) Leadership and employee engagement: proposing research agendas through: a review of literature. Human Resource Development Review 14 (1): 38-63. https://doi.org/10.1177/1534484314560406

Cesário F, Chambel M (2016) Linking organizational commitment and work engagement to employee performance. Proceedings of the International Conference Theory and Application in the Knowledge Economy (TAKE 2016), Eduardo Tomé, Lisbon. Aveiro, Portugal, 6 to 8 July 2016.

Cook S (2012) The essential guide to employee engagement. UK: Kogan Page.

Crawford E, LePine A, Rich B (2010) Linking job demands and resources to employee engagement and burnout: a theoretical extension and meta-analytic test. Journal of Applied Psychology 95 (5): 834-848. https://doi.org/10.1037/a0019364

De Lange A, De Witte H, Notelaers G (2008) Should I stay or should I go? Examining longitudinal relations among job resources and work engagement for stayers versus movers. Work \& Stress 22 (3): 201-223. https://doi. org/10.1080/02678370802390132

Deshwal S (2015) A study of job satisfaction in relation to employee engagement. International Journal of Applied Research 1 (9): 303-304.

Durksen T, Klassen R (2012) Pre-service teachers' weekly commitment and engagement during a final training placement: a longitudinal mixed methods study. Educational \& Child Psychology 29 (4): 32-46.

Geldenhuys M, Laba K, Venter C (2014) Meaningful work, work engagement and organizational commitment. The SA Journal of Industrial Psychology 40 (1): 1-10. https://doi.org/10.4102/ sajip.v40i1.1098

Goffman E (1961) Encounters. Penguine University Books. Harmondsworth.

Gupta M (2017) Corporate Social Responsibility, employeecompany identification, and organizational commitment: Mediation by employee engagement. Current Psychology 36 (1): 101-109. https://doi.org/10.1007/s12144-015-9389-8

Hakanen J, Schaufeli W, Ahola K (2008) The Job Demands-Resources model: a three-year cross-lagged study of burnout, depression, commitment, and work engagement. Work \& Stress 22 (3): 224-241. https://doi.org/10.1080/02678370802379432

Huang Y, Ma Z, Meng Z (2017) High-performance work systems and employee engagement: empirical evidence from China. Asia pacific Journal of Human Resources. https://doi. org/10.1111/1744-7941.12140

Kanste O (2011) Work engagement, work commitment and their association with well-being in health care. Scandinavian Journal of Caring Sciences 25: 754-761. https://doi. org/10.1111/j.1471-6712.2011.00888.x

Kavya M, Padmavathy G (2017) Employee engagement: a review on engagement models. Imperial Journal of Interdisciplinary Research (IJIR) 3 (2): 871-877.

Khalid A, Khalid S (2015) Relationship between organizational commitments, employee engagement, and career satisfaction: a case of University of Gujrat Pakistan. Journal of South Asian Studies 3 (3): 323-330.
Khalid A, Khalid S, Waseem A, Farooqi Y, Nazish A (2015) Relationship between organizational commitment, career satisfaction and employee engagement. European Journal of Business and Social Sciences 3 (11): 172-183.

Khan W (1990) Psychological conditions of personal engagement and disengagement at work. Academy of Management Journal 33: 692-724.

Mackay M, Allen J, Landis R (2017) Investigating the incremental validity of employee engagement in the prediction of employee effectiveness: a meta-analytic path analysis. Human Resource Management Review 27: 108-120. https:// doi.org/10.1016/j.hrmr.2016.03.002

Magem I (2017) A review of the antecedents and consequents of employee engagement. World Academy of Science, Engineering and Technology 11 (4): 773-780.

Meyer J (2016) Handbook of employee commitment. Edward Elgar Publishing Limited, Massachusetts, USA. https://doi. org/10.4337/9781784711740

Meyer J, Allen N (1991) A three-component conceptualization of organizational commitment. Human Resource Management Review 1: 61-89. https://doi.org/10.1016/1053-4822(91)90011-Z

Meyer J, Gagne M (2008) Employee engagement from a selfdetermination theory perspective. Industrial and Organizational Psychology 1: 60-62. https://doi.org/10.1111/j.17549434.2007.00010.x

Oluwalope A, Sunday O (2017) Impact of budgetary participation and organizational commitment on managerial performance in Nigeria. Accounting and Finance Research 6 (3): 48-55. https://doi.org/10.5430/afr.v6n3p48

Park J, Kim J, Yoon S, Joo B (2017) The effects of empowering leadership on psychological well-being and job engagement: the mediating role of psychological capital. Leadership \& Organization Development Journal 38 (3): 350-367. https:// doi.org/10.1108/LODJ-08-2015-0182

Ployhart R, Vandenberg R (2010) Longitudinal research: the theory, design, and analysis of change. Journal of Management 36 (No. 1, January 2010): 94-120. https://doi. org/10.1177/0149206309352110

Rhoades L, Eisenberger R, Armeli S (2001) Affective commitment to the organization: the contribution of perceived organizational support. Journal of Applied Psychology 86: 825-836. https://doi.org/10.1037/0021-9010.86.5.825

Saks A (2006) Antecedents and consequences of employee engagement. Journal of Managerial Psychology 21 (7): 600-619. https://doi.org/10.1108/02683940610690169

Schaufeli W, Bakker A, Salanova M (2006) The Measurement of work engagement with a short questionnaire. Educational and Psychological Measurement 66 (4): 701-716. https://doi. org/10.1177/0013164405282471

Schaufeli W, Salanova M, González-Romá V, Bakker A (2002) The measurement of engagement and burnout: a two sample confirmatory factor analytic approach. Journal of Happiness Studies 3 (1): 71-92. https://doi.org/10.1023/A:1015630930326

Sharma D (2016) A study of ISA engagement at an autonomous management education and research institute, Madhya Pradesh. USHUS Journal of Business Management 15 (2): 23-32.

Singh, S, Karki J (2015) The impact of job engagement and organizational commitment on organizational performance. 
The International Journal of Business \& Management 3 (4): 279-285.

Soane E, Truss C, Alfes K, Shantz A, Rees C, Gatenbytt M (2012) Development and application of a new measure of employee engagement: the ISA engagement scale. Human Resource Development International 15 (5): 529-547. https://doi.org/ $10.1080 / 13678868.2012 .726542$

Stephanie S, Gustomo A (2015) Proposal to improve employee engagement in PT Maju Sentosa by AON Hewitt model and Mercer model. Procedia - Social and Behavioral Sciences 169: 363-370. https://doi.org/10.1016/j.sbspro.2015.01.321

Thang N, Fassin Y (2017) The impact of internal corporate social responsibility on organizational commitment: evidence from
Vietnamese service firms. Journal of Asia-Pacific Business. https://doi.org/10.1080/10599231.2017.1309617

Trofimov A, Bondar I, Trofimova D, Miliutina K, Riabchych I (2017) Organizational commitment factors: role of employee work engagement. Revista ESPACIOS 38 (24): 1-18.

Xanthopoulou D, Bakker A, Demerouti E, Schaufeli W (2009) Reciprocal relationships between job resources, personal resources, and work engagement. Journal of Vocational Behavior 74: 235-244. https://doi.org/10.1016/j.jvb.2008.11.003

Zajkowska M (2012) Employee engagement: how to improve it through internal communication. Human Resources Management \& Ergonomics VI: 104-117. 